\title{
Mapping disulfide bonds from sub-micrograms of purified proteins or micrograms of complex protein mixtures
}

\author{
Shan $\mathrm{Lu}^{1}$, Yong Cao ${ }^{1}$, Sheng-Bo Fan ${ }^{2,3}$, Zhen-Lin Chen ${ }^{2,3}$, Run-Qian Fang ${ }^{2,3}$, \\ Si-Min $\mathrm{He}^{2,3 凶}$, Meng-Qiu Dong ${ }^{1 \bowtie}$ \\ 1 National Institute of Biological Sciences, Beijing, Beijing 102206, China \\ ${ }^{2}$ Key Lab of Intelligent Information Processing of Chinese Academy of Sciences (CAS), University of CAS, Institute of \\ Computing Technology, CAS, Beijing 100190, China \\ ${ }^{3}$ University of Chinese Academy of Sciences, Beijing 100049, China
}

Received: 16 February 2018 / Accepted: 8 March 2018 / Published online: 23 April 2018

\begin{abstract}
Disulfide bonds are vital for protein functions, but locating the linkage sites has been a challenge in protein chemistry, especially when the quantity of a sample is small or the complexity is high. In 2015, our laboratory developed a sensitive and efficient method for mapping protein disulfide bonds from simple or complex samples (Lu et al. in Nat Methods 12:329, 2015). This method is based on liquid chromatography-mass spectrometry (LC-MS) and a powerful data analysis software tool named pLink. To facilitate application of this method, we present step-by-step disulfide mapping protocols for three types of samples-purified proteins in solution, proteins in SDS-PAGE gels, and complex protein mixtures in solution. The minimum amount of protein required for this method can be as low as several hundred nanograms for purified proteins, or tens of micrograms for a mixture of hundreds of proteins. The entire workflow-from sample preparation to LC-MS and data analysis-is described in great detail. We believe that this protocol can be easily implemented in any laboratory with access to a fastscanning, high-resolution, and accurate-mass LC-MS system.
\end{abstract}

Keywords Disulfide, Identification of disulfide bonds, Cross-linking, Mass spectrometry, PLink, PLink-SS

\section{INTRODUCTION}

\section{Functions of disulfide bonds}

Formation of disulfide bonds is a common posttranslational modification that has important biological functions. Many secreted proteins such as antibodies, growth factors, extracellular matrix proteins, and cell surface receptors or transporters, which happen to be of great therapeutic interest, are rich in disulfide bonds. As a structural building block, a disulfide bond covalently links two cysteine residues in the same protein or in different proteins

Shan Lu and Yong Cao have contributed equally to this work.

$\triangle$ Correspondence: smhe@ict.ac.cn (S.-M. He),

dongmengqiu@nibs.ac.cn (M.-Q. Dong) to strengthen the correct conformation of a protein or protein complex, thereby improving stability. Further, the reversible nature of a disulfide bond enables it to act as a molecular switch to regulate the activity of enzymes or transcription factors in response to the redox state of the environment (Hogg 2003). To fully understand the biological function of a disulfide-containing protein and its regulation, it is necessary to map precisely the position of each disulfide bond and to determine the redox state of the two cysteine residues involved-in the disulfide form or as free thiols, or else- under conditions studied.

\section{Methods for disulfide bond analysis}

In the past, a variety of methods had been used for the analysis of protein disulfide bonds including Edman 
degradation (Haniu et al. 1994), diagonal electrophoresis (McDonagh 2009), mutagenesis of cysteine residues coupled with reducing and non-reducing SDSPAGE (Itakura et al. 1994), X-ray crystallography (McCarthy et al. 2000), and nuclear magnetic resonance spectroscopy (Sharma and Rajarathnam 2000). However, none of these methods are ideal; the ones that can provide precise linkage information of disulfide bonds demand highly specialized skills and devoted efforts of structural biologists, and the ones that can be executed in an average biology lab do not afford linkage information directly. Further, they usually require milligrams of purified proteins, and none of them work on complex samples.

In recent years, rapid technological development in liquid chromatography-mass spectrometry (LC-MS) has made it possible to map disulfide bonds from as little as micrograms of proteins in a relatively high throughput way (Choi et al. 2009; Götze et al. 2012; Huang et al. 2014; Liu et al. 2014, 2017a; Murad and Singh 2013; Wang et al. 2014; Wefing et al. 2006; Wu et al. 2008; Xu et al. 2007). Among the methods in this category, the more straightforward ones do not reduce disulfide bonds prior to LC-MS analysis, so the linkage information can be extracted from the fragmentation spectra of peptides containing disulfide bonds. Different fragmentation methods including collision-induced dissociation (CID), higher-energy collisional dissociation (HCD), electron-transfer dissociation (ETD), and electrontransfer/higher-energy collision dissociation (EThcD) (Liu et al. 2014) have been used to varying degrees of success. Table 1 summarizes the data analysis tools that have been developed for LC-MS analysis of disulfide bonds. Most of them are designed to identify disulfide bonds directly from fragmentation spectra. From these endeavors, two challenges have become apparent, one is to identify all the disulfide bonds in a protein and the other is to identify disulfide bonds at a proteome scale, that is, from highly complex samples such as cell lysates, isolated mitochondria, or secretomes. Another constant problem is false identification of disulfide bonds, the source of which may be faulty data analysis or disulfide bond scrambling during sample preparation.

Table 1 Software tools for MS-based disulfide bond identification

\begin{tabular}{|c|c|c|c|c|}
\hline Software & $\begin{array}{l}\text { MS function } \\
\text { required }\end{array}$ & $\begin{array}{l}\text { Type of } \\
\text { data } \\
\text { analyzed }\end{array}$ & Advantages (A) and limitations (L) & References \\
\hline SearchXLinks & MALDI source & MS1 & L: Works only for very simple samples & $\begin{array}{l}\text { Wefing et al. } \\
\quad \text { (2006) }\end{array}$ \\
\hline MassMatrix & CID or HCD & $\begin{array}{l}\text { CID or HCD } \\
\text { MS2 }\end{array}$ & $\begin{array}{l}\text { A: Complex forms of disulfide bonds are taken into consideration; } \\
\text { L: Only for low-complexity samples digested using specific proteases }\end{array}$ & $\begin{array}{l}\text { Xu et al. } \\
\quad(2007)\end{array}$ \\
\hline DBond & CID or HCD & $\begin{array}{l}\text { CID or HCD } \\
\text { MS2 }\end{array}$ & $\begin{array}{l}\text { A: Disulfide-specific fragment ions are considered; } \\
\text { L: No automatic FDR control, only for low-complexity samples }\end{array}$ & $\begin{array}{l}\text { Choi et al. } \\
\text { (2009) }\end{array}$ \\
\hline MS2DB+ & CID or HCD & $\begin{array}{l}\text { CID or HCD } \\
\text { MS2 }\end{array}$ & L: No FDR control & $\begin{array}{l}\text { Murad and } \\
\text { Singh } \\
\text { (2013) }\end{array}$ \\
\hline MixDB & CID or HCD & $\begin{array}{l}\text { CID or HCD } \\
\text { MS2 }\end{array}$ & $\begin{array}{l}\text { A: Automatic FDR control, can handle large protein databases; } \\
\text { L: Not easy to use, not tested with real-world samples }\end{array}$ & $\begin{array}{l}\text { Wang et al. } \\
\text { (2014) }\end{array}$ \\
\hline RADAR & HCD & HCD MS2 & $\begin{array}{l}\text { A: Specific dimethyl labeling at peptide N-terminus improves accuracy } \\
\text { of identification; } \\
\text { L: Requires labeling after digestion; No FDR control }\end{array}$ & $\begin{array}{l}\text { Huang et al. } \\
\quad \text { (2014) }\end{array}$ \\
\hline PepFinder & $\begin{array}{l}\text { EThcD or high- } \\
\text { resolution ETD }\end{array}$ & HCD MS2 & $\begin{array}{l}\text { L: One reduced and one non-reduced samples need to be analyzed side } \\
\text { by side, works only for low-complexity samples }\end{array}$ & $\begin{array}{l}\text { From } \\
\text { Thermo } \\
\text { Scientific }\end{array}$ \\
\hline SlinkS & $\begin{array}{l}\text { EThcD and high- } \\
\text { resolution ETD }\end{array}$ & $\begin{array}{l}\text { ETD or } \\
\text { EThcD } \\
\text { MS2 }\end{array}$ & $\begin{array}{l}\text { A: ETD and EThcD complement each other; } \\
\text { L: Requires a unique ion pattern, efficiency of ETD varies depending on } \\
\text { the peptides }\end{array}$ & $\begin{array}{l}\text { Liu et al. } \\
\text { (2014) }\end{array}$ \\
\hline pLink-SS & $\begin{array}{l}\text { HCD or high- } \\
\text { resolution ETD }\end{array}$ & HCD MS2 & $\begin{array}{l}\text { A: Automatic workflow with FDR estimation, disulfide-specific ions and } \\
\text { internal ions are considered, works for complex samples; } \\
\text { L: highly complex forms such as three peptides inter-linked through } \\
\text { two disulfide bonds cannot be identified }\end{array}$ & $\begin{array}{l}\text { Lu et al. } \\
\quad(2015)\end{array}$ \\
\hline
\end{tabular}




\section{About the method used in this protocol}

With these problems in mind, we developed a method that enabled us to prevent most, if not all disulfide scrambling events and to identify all the native disulfide bonds of a single protein or a mixture of ten proteins from micrograms or even a few hundred nanograms of samples. It also enabled us to map native disulfide bonds at a proteome scale, for instance, 199 disulfide bonds were identified from a periplasmic fraction of Escherichia coli cells and 568 disulfide bonds were identified from proteins secreted by human umbilical vein endothelial cells. This method was published in 2015 (Lu et al. 2015). Since then, to our knowledge, it has been used successfully in dozens of studies and seven of them have been published (Hartman et al. 2016; Hung et al. 2016; Liu et al. 2017b; Mauney et al. 2017; Wang et al. 2016; Wu et al. 2016, 2017). The three key components of this method are as follows. First, disulfide bond scrambling is prevented by blocking free thiols with $N$-ethylmaleimide (NEM) and by maintaining an acidic $\mathrm{pH}$ throughout the sample preparation process, the latter of which includes precipitating freshly prepared protein samples with trichloroacetic acid (TCA) as early as possible and carrying out all protease digestions at pH 6.5 (Fig. 1). Second, to identify all the disulfide bonds of a protein, multiple proteases are utilized, even the non-specific ones such as proteinase $\mathrm{K}$. This is because some disulfide bonds may be present in a complex form that is difficult to identify if the sample is digested only with Lys-C and trypsin (Fig. 2). Last and the most important, a data analysis program called pLink-SS has been developed and carefully tuned to identify disulfide-bonded peptides from HCD spectra. The types of disulfide-bonded peptides that can be identified using pLink-SS are shown in Fig. 3. Presently, pLink-SS has been incorporated into pLink 2, which is an upgraded version of pLink and remains free for academic users. pLink 2 is $\sim 40$ times faster than pLink, with a friendly graphical interface and some further improvements in accuracy. pLink 2 was officially released on January 1, 2018 and can be downloaded at http://pfind.ict.ac.cn/ software/pLink/.

In this paper, we present a step-by-step disulfide mapping protocol using the method we developed in 2015. As shown in Fig. 4, this protocol contains three alternative sub-protocols that are each optimized for low-complexity samples in solution, protein gel bands, or high-complexity samples.
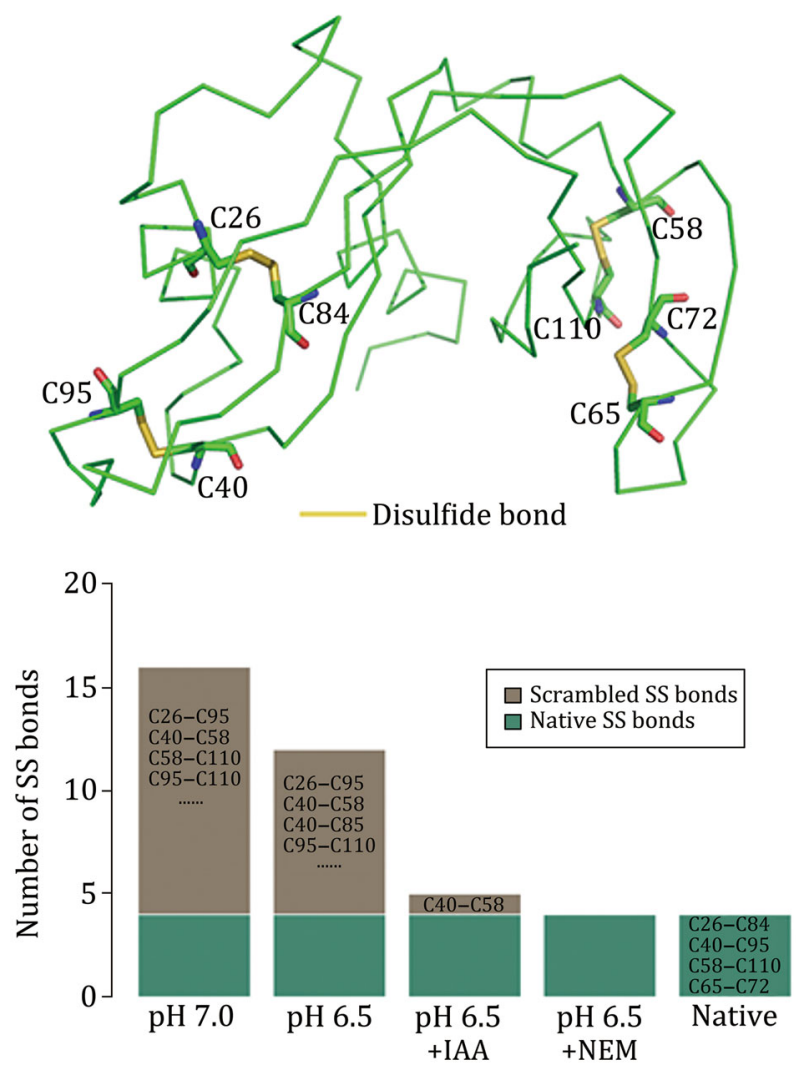

Fig. 1 Non-native disulfide bonds of RNase A are abolished by blocking free thiols with NEM and carrying out protease digestions at $\mathrm{pH} 6.5$

\section{REAGENTS}

\section{Chemicals}

- Acetic acid (J. T. Baker, cat. no. 9508)

- Acetone (J. T. Baker, cat. no. 9002-02)

- Acetonitrile (ACN), HPLC grade (Fisher Scientific, cat. no. A998)

- Ammonium acetate, $7.5 \mathrm{~mol} / \mathrm{L}$ solution (SigmaAldrich, cat. no. A2706)

- BCA protein assay kit (Pierce, cat. no. 23228)

- Formic acid (FA) (J. T. Baker, cat. no. 0129)

- Frit kit (including formamide, $\mathrm{Kasil}^{\circledR}{ }^{\circledR}-1$ and Kasil ${ }^{\circledR}$ 1624 potassium silicate solution and a ceramic tubing cutter, from Next Advance)

- Guanidine hydrochloride (GndCl) (Sigma-Aldrich, cat. no. G3272)

- N-ethylmaleimide (NEM) (Pierce, cat. no. 23030)

- Trichloroacetic acid (TCA), $6.1 \mathrm{~N}$ or $100 \%(w / v)$ solution (Sigma-Aldrich, cat. no. T0699)

- Tris (Amresco, cat. no. 0497) 
Trypsin + Lys-C

\begin{tabular}{|c|c|}
\hline \multicolumn{2}{|l|}{26} \\
\hline & 72 \\
\hline 84 & \\
\hline
\end{tabular}

\begin{tabular}{|c|c|}
\hline t & 58 \\
\hline 40 & \\
\hline
\end{tabular}

Trypsin + Lys-C + Glu-C

\begin{tabular}{|c|c|}
\hline \multicolumn{2}{|c|}{26} \\
\hline & 72 \\
\hline 84 & \\
\hline
\end{tabular}
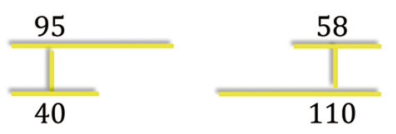

Non-specific protease
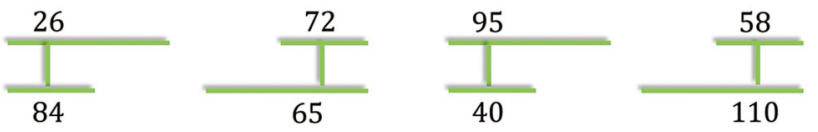

Fig. 2 Digestion of RNase A with Lys-C and trypsin results in a complex form comprising three peptides linked together through two disulfide bonds, which cannot be identified using existing software tools. Digestion with additional proteases generates simpler forms that can be identified

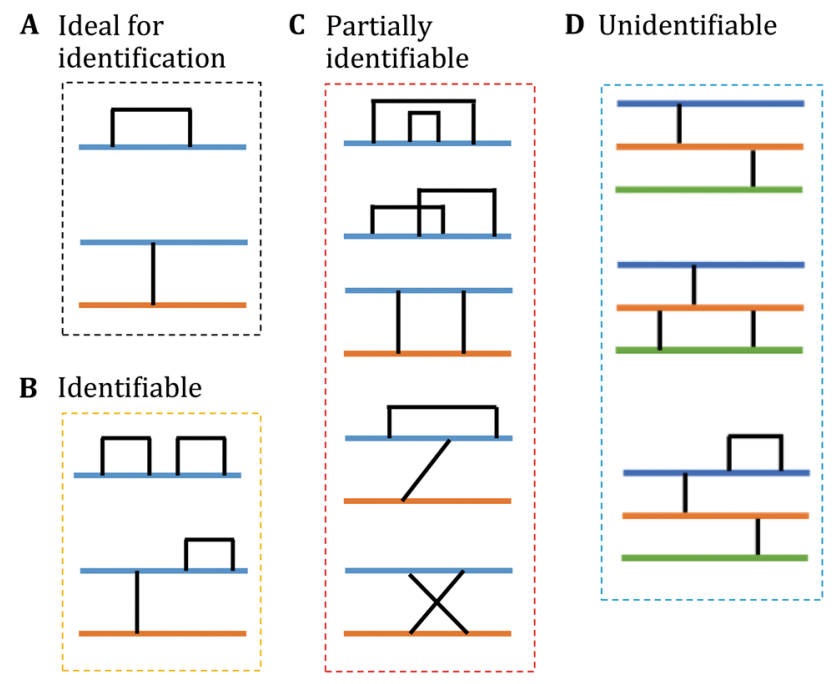

Fig. 3 Disulfide bonds that can or cannot be identified using pLink. A Peptides containing a single disulfide bond can be identified with precise linkage information. B Disulfide bonds can be identified with precise linkage information in some cases. C The presence of disulfide bonds may be identified but without linkage information. D Disulfide bonds cannot be identified

- Urea (Sigma-Aldrich, cat. no. U0631)

- Water, HPLC grade (Sigma-Aldrich, cat. no. V270733)

\section{Enzymes}

- Asp-N (Promega, cat. no. V162A)

- Elastase (Sigma-Aldrich, cat. no. E7885)

- Glu-C (Promega, cat. no. V1651)

- Lys-C (Wako, cat. no. 125-05061)
- PNGase F (NEB, cat. no. P0704)

- Proteinase K (Sigma-Aldrich, cat. no. P3910)

- Subtilisin (Sigma-Aldrich, cat. no. 43538)

- Trypsin (Promega, cat. no. V5117)

\section{Supplies}

- Fused silica capillary tubing with a polyimide coating for reverse-phase (RP) liquid chromatography-mass spectrometry (LC-MS), 75- $\mu \mathrm{m}$ inner diameter (ID), 360- $\mu \mathrm{m}$ outer diameter (OD) (Polymicro Technologies, Part No. 1068150019)

- Fused silica capillary tubing for off-line SCX fractionation, 200- $\mu \mathrm{m}$ ID, 360- $\mu \mathrm{m}$ OD (Polymicro Technologies, Part No. 1068150204)

- MicroTight Union for 360- $\mu \mathrm{m}$ OD tubing (Upchurch, Part No. P-772)

- Luna C18 resin, $3 \mu \mathrm{m}$ particle size, $100 \AA$ A pore size (Phenomenex, cat. no. 04A-4251)

- Luna SCX resin, $5 \mu \mathrm{m}$ particle size, $100 \AA$ Å pore size, (Phenomenex, cat. no. 04A-4398)

- Sample vials for LC-MS (Thermo La-pha-pak, cat. no. 11190933)

- Welch Ultimate UHPLC-XB-C18 resin, C18, $1.8 \mu \mathrm{m}$ particle size, $120 \AA$ pore size (Welch Materials, Shanghai, cat. no. UHP101.02)

- YMC*GEL, C18, $10 \mu \mathrm{m}$ particle size, pore size $120 \AA$ (YMC, cat no. AQ12S11)

\section{BUFFERS}

- $0.5 \mathrm{~mol} / \mathrm{L}$ Tris buffer, $\mathrm{pH} 6.5$

- Strong cation exchange (SCX) elution buffers: 25, 50, $100,250,500 \mathrm{mmol} / \mathrm{L}$, and $1 \mathrm{~mol} / \mathrm{L}$ ammonium acetate in $5 \% \mathrm{ACN}, 0.1 \% \mathrm{FA}$

- For SCX fractionation: $80 \%$ ACN, 0.1\% FA

- For in-gel digestion, peptide extraction (Buffer I): 0.5\% FA, 50\% ACN

- For in-gel digestion, peptide extraction (Buffer II): $1 \%$ FA, $75 \%$ ACN

- LC mobile phase A (Buffer A): $\mathrm{H}_{2} \mathrm{O} / \mathrm{FA}(100 / 0.1, v / v)$, good at room temperature (RT) for several weeks

- LC mobile phase B (Buffer B): ACN/FA (100/0.1, v/v), good at RT for several months

\section{EQUIPMENT}

\section{Small equipment}

- ThermoMixer, a bench top temperature-controlled tube mixer (Eppendorf) 
A

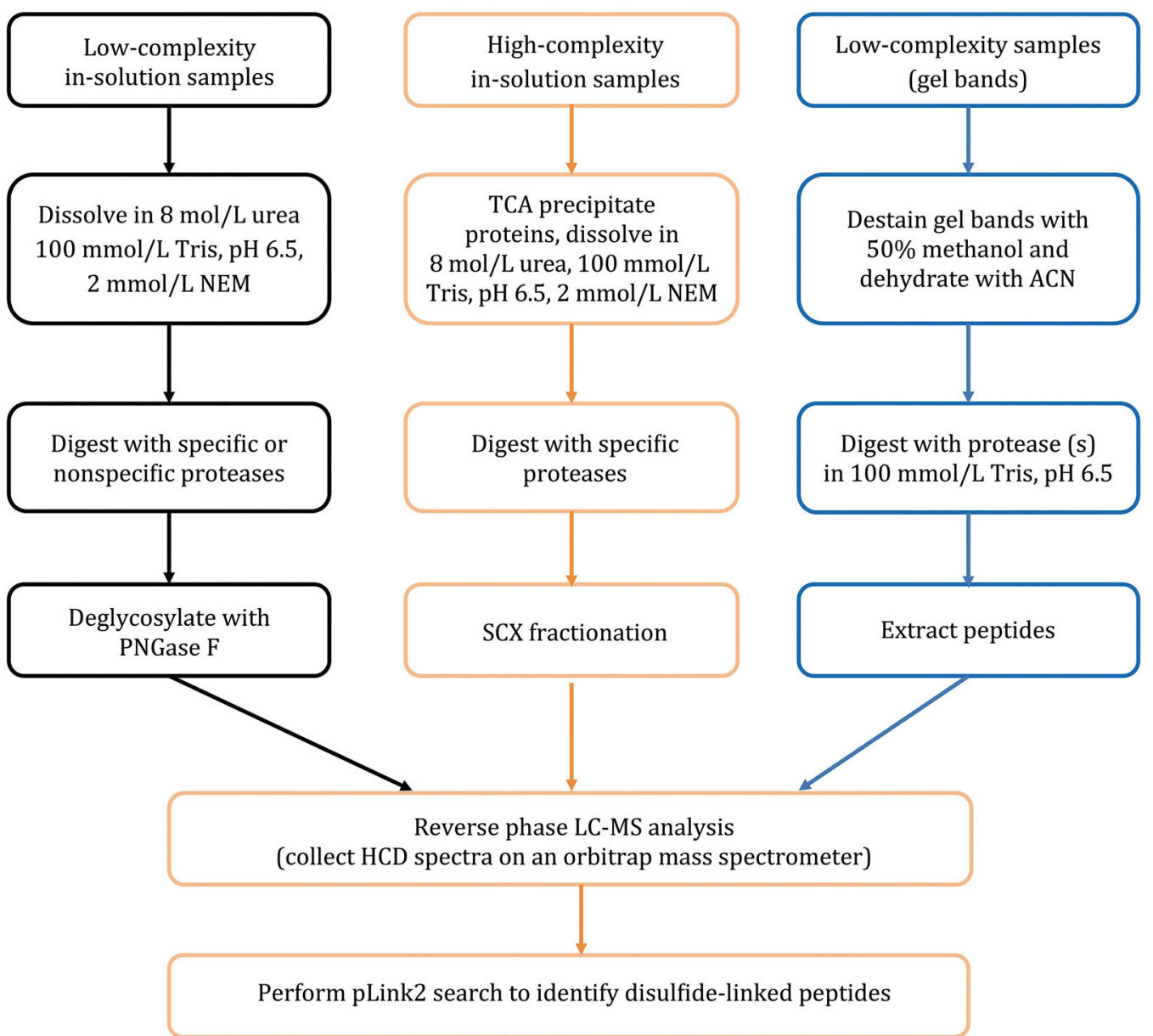

C

\section{.}


ii. Mount the tubing into the Sutter laser puller with the clear segment in the path of the laser beam and pull a $5-\mu \mathrm{m}$ tip.

Note: The exact setup of the pulling program varies between instruments and over time. The example below serves as a starting point for optimization.

cycle 1 HEAT $=270$, FIL $=0$, VEL $=35$, $\mathrm{DEL}=128, \mathrm{PUL}=0$

cycle 2 HEAT $=260$, FIL $=0$, VEL $=30$, $\mathrm{DEL}=128, \mathrm{PUL}=0$

cycle 3 HEAT $=250$, FIL $=0$, VEL $=25$, $\mathrm{DEL}=128, \mathrm{PUL}=0$

cycle 4 HEAT $=240$, FIL $=0$, VEL $=25$, $\mathrm{DEL}=128, \mathrm{PUL}=0$

iii. Dismount the two empty columns each with a pulled tip.

iv. In a tube or a glass vial that will fit inside the pressure injection cell, add a small amount (roughly the size of a grain of millet) of Welch UHPLC-XB-C18 resin into methanol and make a slurry.

v. Using the column packing setup, pack the $3-\mu \mathrm{m}$ Luna C18 resin into a 75- $\mu$ m ID analytical column with a pulled tip for a length of $\sim 2 \mathrm{~cm}$, then switch the resin to $1.8-\mu \mathrm{m}$ Welch UHPLC-XB-C18, and pack another $10-12 \mathrm{~cm}$. The total length of the reverse phase is $13 \pm 1 \mathrm{~cm}$.

vi. Condition the column by running a RP gradient through it and ending with Buffer A wash.

\section{RP trap column}

i. Take from the Frit kit $60 \mu \mathrm{l}$ Kasil-1624 and $20 \mu \mathrm{l}$ Kasil-1, mix well in a small tube, then add $20 \mu \mathrm{l}$ formamide, mix well.

ii. Cut a 20-cm-long 75- $\mu \mathrm{m}$ ID fused silica tubing, dip one end into the mixture just made, and then pull out immediately. Inspect the column for the appearance of a segment of liquid inside.

iii. Place the column in an oven of $100^{\circ} \mathrm{C}$ for $4-12 \mathrm{~h}$ to obtain a porous frit at one end of the column. Before polymerization, handle the column with great care to avoid displacing the liquid away from the end. Keep fritted columns at RT for long-term storage.

iv. Before packing a column, cut the frit end with a tubing cutter so only 1-2 mm frit is left.

v. In a tube or a glass vial that will fit inside the pressure injection cell, add a small amount (roughly the size of a grain of millet) of Luna C18 resin into methanol and make a slurry.

vi. Using the column packing setup, pack the $10-\mu \mathrm{m}$ YMC*GEL C18 resin into an empty, $75-\mu \mathrm{m}$ ID column against the frit for a length of $7 \pm 1 \mathrm{~cm}$.

vii. Condition the trap column by passing Buffer A through it.

\section{SCX fractionation column}

i. Take from the Frit kit $60 \mu \mathrm{l}$ Kasil-1624 and $20 \mu \mathrm{l}$ Kasil-1, mix well in a small tube, then add $20 \mu \mathrm{l}$ formamide, mix well.

ii. Cut a 25-cm-long 200- $\mu \mathrm{m}$ ID fused silica tubing, dip one end into the mixture just made, and then pull out immediately. Inspect the column for the appearance of a segment of liquid inside.

iii. Place the column in an oven of $100{ }^{\circ} \mathrm{C}$ for $4-12 \mathrm{~h}$ to obtain a porous frit at one end of the column. Before polymerization, handle the column with great care to avoid displacing the liquid away from the end. Keep fritted columns at RT for long-term storage.

iv. Before packing a column, cut the frit end with a tubing cutter so only 1-2 mm frit is left.

v. In a tube or a glass vial that will fit inside the pressure injection cell, add a small amount (roughly the size of a grain of millet) of Luna SCX resins into methanol and make a slurry.

vi. Using the column packing setup, pack the SCX resins into an empty column against the frit for a length of 2-3 cm.

vii. Pass Buffer A through the column to pack the SCX segment more tightly.

viii. Change the packing material to $3-\mu \mathrm{m}$ Luna C18 resin and pack a RP segment of $2-3 \mathrm{~cm}$.

ix. Condition the SCX column by passing Buffer A through it.

\section{SOFTWARE}

- Computer workstation with Microsoft Windows 7 or a newer operating system

- NET framework 4.5

- MSFileReader, both 32 and 64-bit version, for pLink 2 to access the raw file

- pLink 2, version 2.3.0

- Python 3.6 


\section{REAGENT SETUP}

\section{1 mol/L NEM stock solution}

Dissolve $125.1 \mathrm{mg}$ of solid $\mathrm{N}$-ethylmaleimide in $1 \mathrm{ml}$ of $100 \% \mathrm{ACN}$, dispense into $4-\mu$ l aliquots, store in a desiccator at $-20{ }^{\circ} \mathrm{C}$, and use within two months. Each aliquot is for a single use.

\section{$8 \mathrm{~mol} / \mathrm{L}$ urea in $100 \mathrm{mmol} / \mathrm{L}$ Tris pH 6.5}

Dissolve $240 \mathrm{mg}$ of solid urea in $100 \mu \mathrm{l} 0.5 \mathrm{~mol} / \mathrm{L}$ Tris at $\mathrm{pH} 6.5$ and $220 \mu \mathrm{H}_{2} \mathrm{O}$. Prepare the fresh solution each time to minimize urea degradation and subsequent carbamylation of proteins or peptides.

\section{Stock solutions of proteases}

Prepare $0.5 \mu \mathrm{g} / \mu \mathrm{L}$ trypsin or a different protease in $\mathrm{H}_{2} \mathrm{O}$ or a stock buffer specified by the vendor, dispense into aliquots of $10 \mu \mathrm{l}$ or less, and store at $-80{ }^{\circ} \mathrm{C}$. Ideally, each aliquot is for a single use.

\section{EQUIPMENT SETUP}

\section{LC-MS}

On Q-Exactive, generate a MS method as follows: spray voltage $2.0-2.3 \mathrm{kV}$, data-dependent mode, full scan resolution 140,000, MS2 scan resolution 17,500, isolation window $2.0 \mathrm{~m} / \mathrm{z}$, AGC target at $1 \mathrm{e} 6$ for FTMS full scan and $5 \mathrm{e} 4$ for MS2, minimal signal threshold for MS2 at $4 \mathrm{e} 4$; normalized collision energy at $27 \%$; peptide match preferred, and HCD spectra were collected for the ten most intense precursors carrying $+3,+4, \ldots$, or +7 positive charges, dynamic exclusion $60 \mathrm{~s}$. To increase the identification of loop-linked disulfide bonds, a technical repeat run is recommended in which +2 precursors were also included. So, generate another MS method that is the same as above except that +2 precursors are not excluded.

On Easy-nLC 1000 UHPLC, set the sample loading and RP gradient method as follows. For each sample, $0.5 \mu \mathrm{g}$ of digested peptides are loaded onto the trap column at $1 \mu \mathrm{l} / \mathrm{min}$ and desalted with $10 \mu \mathrm{l}$ of Buffer A. The peptides are separated through a 100 min linear gradient from 100\% Buffer A to 30\% Buffer B and then going up to $100 \%$ Buffer B in $1 \mathrm{~min}$, followed by a 3-min $100 \%$ Buffer B wash before returning to $100 \%$ Buffer A in 2 min and maintaining at $100 \%$ Buffer A for $4 \mathrm{~min}$. Set the flow rate at $250 \mathrm{nl} / \mathrm{min}$.

\section{SOFTWARE SETUP}

(1) MSFileReader: Instructions are available at https:// github.com/pFindStudio/pLink2/wiki/FAQ\#howto-install-msfilereader.

(2) pLink 2: Free download at http://pfind.ict.ac.cn/ software/pLink/index.html\#Downloads. Double click the installation package, choose the language and directory. pLink 2 will then finish the installation automatically.

[CRITICAL] License is required to run pLink 2 the first time. To receive the license file, send an e-mail to pLink@ict.ac.cn. Follow instructions during installation. The pLink 2 installation package includes pParse, a MS data conversion tool, and pLabel-a very convenient and powerful tool for annotating peaks in a MS2 spectrum. Once pLink 2 is installed, pParse and pLabel are ready.

(3) Python 3.6: Installation instructions are available at https://www.python.org/.

(4) Python package "openpyxl" and "xlrd": Enter in the following commands in windows "Command Prompt":

- pip3 install openpyxl,

- pip3 install xlrd.

[CRITICAL] Here we provide a python script to organize the pLink 2 search results and generate a simple and informative report file. To run this script, Python 3.6 and packages openpyxl and xlrd are required.

(5) Python script SS_sim.py: Download from https:// github.com/daheitu/pLink2_ss_results_analysis. github.io.git.

\section{SAMPLE PREPARATION}

\section{In-solution digestion (low-complexity samples) [TIMING 1 day]}

Note: Low-complexity samples refer to a purified protein or a protein complex of no more than 50 subunits.

(1) Determine the concentration of a freshly purified protein sample using a BCA protein assay kit. Do not rely on $O D_{280}$ measurements.

(2) Based on the sequences of the proteins in question and the amount of proteins available, decide which proteases to use and how many digestions to carry out. Common choices are Lys-C/trypsin, Lys-C/trypsin/ Glu-C, Lys-C/Asp-N, and Lys-C/trypsin/Asp-N; 
and additional options include Lys-C/elastase, subtilisin, and proteinase $\mathrm{K}$.

(3) For each digestion, take $4 \mu \mathrm{g}$ of a freshly prepared protein sample and precipitate with 25\% TCA. Specifically, add $1 / 3$ volume of $100 \%$ TCA, mix well, and leave on ice for $30 \mathrm{~min}$ to overnight. Spin at $4{ }^{\circ} \mathrm{C}$ in a bench top centrifuge at top speed for $30 \mathrm{~min}$ to pellet proteins, wash with $0.5 \mathrm{ml}$ cold acetone twice, and air dry the pellet.

(4) Dissolve $4 \mu \mathrm{g}$ of the freshly precipitated protein sample in $10 \mu \mathrm{l}$ of $8 \mathrm{~mol} / \mathrm{L}$ urea, $100 \mathrm{mmol} / \mathrm{L}$ Tris, $\mathrm{pH}$ 6.5; add NEM to a final concentration $2 \mathrm{mmol} / \mathrm{L}$; and incubate at $37{ }^{\circ} \mathrm{C}$ for $2 \mathrm{~h}$.

[CRITICAL] NEM can gradually hydrolyze in water and lose activity, so $15 \mathrm{~min}$ before use, transfer a frozen aliquot of $1 \mathrm{~mol} / \mathrm{L}$ NEM to a desiccator at RT.

\section{[? TROUBLESHOOTING]}

(5) Digest the protein(s) with one or more proteases of choice. The digestion conditions of various proteases are listed in Table 2. If two or more proteases are to be combined in one digestion, perform the digestion sequentially to reduce mutual digestion between proteases. For example, if a sample is to be digested with Lys-C/trypsin/ Glu-C, digest with Lys-C first in $8 \mathrm{~mol} / \mathrm{L}$ urea at $37{ }^{\circ} \mathrm{C}$ for $2 \mathrm{~h}$; then dilute to $2 \mathrm{~mol} / \mathrm{L}$ urea with $30 \mu \mathrm{l}$ of $100 \mathrm{mmol} / \mathrm{L}$ Tris, $\mathrm{pH}$ 6.5, add trypsin, and incubate at $37{ }^{\circ} \mathrm{C}$ for $12 \mathrm{~h}$; and lastly, dilute to $1 \mathrm{~mol} / \mathrm{L}$ urea with $40 \mu \mathrm{l}$ of $100 \mathrm{mmol} / \mathrm{L}$ Tris, $\mathrm{pH}$ 6.5, add Glu-C, and incubate at $37{ }^{\circ} \mathrm{C}$ for $12 \mathrm{~h}$. [CRITICAL] As disulfide-linked proteins are often resistant to proteases, digestion in the presence of a high concentration of denaturant is necessary. Therefore, Lys-C digestion in $8 \mathrm{~mol} / \mathrm{L}$ urea usually precedes other proteases except for subtilisin and proteinase $\mathrm{K}$, both of which have activity high enough for digesting any protein, even at $\mathrm{pH}$ 6.5. Avoid under- or over-digestion.

\section{[? TROUBLESHOOTING]}

(6) To remove glycosylation, which may interfere with data analysis, add PNGase F (112 NEB units per $6 \mu \mathrm{g}$ of proteins) to the digest and incubate at

\section{$37{ }^{\circ} \mathrm{C}$ for $2 \mathrm{~h}$.}

[CRITICAL] Many secreted proteins are glycosylated and disulfide-linked. Unexpected glycosylation prevents identification of disulfide bonds. PNGase $\mathrm{F}$ remains its activity in $2 \mathrm{~mol} / \mathrm{L}$ urea or $1 \mathrm{~mol} / \mathrm{L} \mathrm{GndCl}$ but loses most of its activity in $2 \mathrm{~mol} / \mathrm{L} \mathrm{GndCl}$, so dilute the proteinase $\mathrm{K}$ digest with an equal volume of $100 \mathrm{mmol} / \mathrm{L}$ Tris, $\mathrm{pH} 6.5$ before adding PNGase $\mathrm{F}$.

(7) Quench the reaction by adding $90 \%$ FA to a $5 \%$ final concentration.

For LC-MS analysis of a low-complexity sample, load $0.2-0.5 \mu \mathrm{g}$ of protein for a single run.

[PAUSE POINT] The samples can be stored up to several weeks at $-20{ }^{\circ} \mathrm{C}$ or $-80{ }^{\circ} \mathrm{C}$ before LC-MS analysis.

\section{In-solution digestion (high-complexity samples) [TIMING 1-2 days]}

Note: High-complexity samples refer to whole-cell lysates, subcellular fractions, or crude immunoprecipitated proteins that contain hundreds or thousands of proteins.

(1) Precipitate $30 \mu \mathrm{g}$ of a freshly prepared protein sample with $25 \%$ TCA and wash with cold acetone as described above. For details, see "In-solution digestion (low-complexity samples)".

(2) Dissolve precipitated proteins in $25 \mu \mathrm{l}$ of $8 \mathrm{~mol} / \mathrm{L}$ urea, $100 \mathrm{mmol} / \mathrm{L}$ Tris, pH 6.5; add NEM to a final concentration of $2 \mathrm{mmol} / \mathrm{L}$; and incubate at $37{ }^{\circ} \mathrm{C}$ for $2 \mathrm{~h}$.

[CRITICAL] Sonication is recommended to help dissolve proteins in $8 \mathrm{~mol} / \mathrm{L}$ urea. $20-40 \mu \mathrm{g}$ proteins are acceptable.

(3) Digestion with Lys-C/trypsin/Glu-C. For details, see "In-solution digestion (low-complexity samples)".

[CRITICAL] Avoid using proteases of poor specificity to digest high-complexity samples as it will lead to search space explosion in data analysis, reducing the speed and sensitivity of identification.

Table 2 Proteases digestion conditions

\begin{tabular}{llllllll}
\hline & Lys-C & Trypsin & Glu-C & Asp-N & Elastase & Subtilisin & Proteinase K \\
\hline Denaturant & $8 \mathrm{~mol} / \mathrm{L}$ urea & $2 \mathrm{~mol} / \mathrm{L}$ urea & $1 \mathrm{~mol} / \mathrm{L}$ urea & $2 \mathrm{~mol} / \mathrm{L}$ urea & $2 \mathrm{~mol} / \mathrm{L}$ urea & $2 \mathrm{~mol} / \mathrm{L} \mathrm{GndCl}$ & $2 \mathrm{~mol} / \mathrm{L} \mathrm{GndCl}$ \\
Digestion time & $4 \mathrm{~h}$ & $12 \mathrm{~h}$ & $12 \mathrm{~h}$ & $12 \mathrm{~h}$ & $8 \mathrm{~h}$ & $4 \mathrm{~h}$ & $4 \mathrm{~h}$ \\
Enzyme: Protein $(w: w)$ & $1: 100$ & $1: 20$ & $1: 40$ & $1: 50$ & $1: 20$ & $1: 20$ & $1: 20$ \\
\hline
\end{tabular}

Digestion temperature is $37^{\circ} \mathrm{C}$ for all 
In our experience, adding Glu-C on top of Lys-C/ trypsin digestion significantly increases the number of disulfide bond identifications. If desired, Lys$\mathrm{C} /$ trypsin/Asp- $\mathrm{N}$ is another option.

(4) Quench the digestion by adding FA to a final concentration of $5 \%$.

(5) Using a pressure injection cell, load digested peptides onto a SCX fractionation column. For better flow-rate control, connect the fritted end of the SCX column to an empty $75-\mu \mathrm{m}$ ID, $360-\mu \mathrm{m}$ OD fused silica tubing (with a pulled tip if necessary) with a MicroTight union. Wash the column with $15 \mu \mathrm{l}$ of $0.1 \% \mathrm{FA}$, followed by $15 \mu \mathrm{l} 80 \% \mathrm{ACN}$, $0.1 \% \mathrm{FA}$, then $10 \mu \mathrm{l}$ of Buffer $\mathrm{A}$, at a flow rate of $1 \mu \mathrm{l} / \mathrm{min}$. Now the peptides are bound to SCX resin and ready to be fractionated.

(6) Elute sequentially with $20 \mu \mathrm{l}$ of $5 \%$ Buffer B (5\% ACN, $0.1 \% \mathrm{FA}$ ) containing $25,50,75,100,500$, or $1000 \mathrm{mmol} / \mathrm{L}$ ammonium acetate, $\mathrm{pH} \mathrm{2-3}$, at a flow rate of $1.0-2.0 \mu \mathrm{l} / \mathrm{min}$. Collect each of the six fractions into an Eppendorf tube. Load one-fifth of each fraction for a subsequent reverse-phase LCMS run.

[PAUSE POINT] The samples can be stored up to several weeks at $-20{ }^{\circ} \mathrm{C}$ or $-80{ }^{\circ} \mathrm{C}$ before LC-MS analysis.

\section{In-gel digestion (protein bands of interest) [TIMING 1-2 days]}

[CRITICAL] To maintain protein disulfide bonds during SDS-PAGE analysis, reducing reagents are forbidden and $20 \mathrm{mmol} / \mathrm{L}$ NEM must be present in the sample loading buffer.

(1) Excise the gel band of interest and dice into $1 \mathrm{~mm}^{3}$ pieces.

(2) Destain the gel with $50 \%$ methanol and wash with $\mathrm{ddH}_{2} \mathrm{O}$ twice. Then dehydrate with $100 \%$ acetonitrile.

(3) Rehydrate into $100 \mathrm{mmol} / \mathrm{L}$ Tris, pH 6.5 containing $0.5 \mathrm{mmol} / \mathrm{L} \mathrm{NEM}, 5 \mathrm{ng} / \mu \mathrm{L}$ Lys-C, and $10 \mathrm{ng} / \mu \mathrm{L}$ of another protease of choice-trypsin, Glu-C, or Asp-N.

(4) Digest for $12 \mathrm{~h}$ at $37^{\circ} \mathrm{C}$.

(5) Extract peptides with $50-100 \mu \mathrm{l}$ of extraction Buffer I (50\% ACN, 0.5\% FA) and then with $50-100 \mu \mathrm{l}$ of extraction Buffer II (75\% ACN, 1\% $\mathrm{FA})$.

(6) Concentrate the sample to $4-8 \mu$ in a SpeedVac ${ }^{\mathrm{TM}}$ concentrator at 2.5 Torr, RT. If the sample dries out accidently, reconstitute the sample with $6 \mu \mathrm{l}$ of $0.1 \%$ FA, $1 \%$ ACN. Calculate or estimate the amount of protein in the gel band and prepare to load about $0.2 \mu \mathrm{g}$ for LC-MS analysis. If this is not practical, load $1 / 5$ of the sample.

[PAUSE POINT] The samples can be stored up to several weeks at $-20{ }^{\circ} \mathrm{C}$ or $-80{ }^{\circ} \mathrm{C}$ before LC-MS analysis.

\section{LC-MS ANALYSIS [TIMING 1-30 h, DEPENDING ON SAMPLE COMPLEXITY]}

[CRITICAL] Each sample is to be analyzed twice; reject $2+$ precursor ions in one (to increase identification of inter-linked peptides) but not in the other (to increase identification of loop-linked peptides).

(1) Connect the trap column and the analytical column to an Easy-nLC 1000 UHPLC according to the 2-column setup scheme. Cut the tail end of each column to reduce dead volumes.

(2) Connect the 2-column setup to the nano-ESI source of the Q-Exactive ${ }^{\mathrm{TM}}$ mass spectrometer and position the tip of the analytical column $\sim 0.5 \mathrm{~cm}$ away from the opening of the heated capillary. Adjust the tip to ensure a steady spray.

(3) Pre-equilibrate the columns with Buffer A and make sure there is no air bubble.

(4) Transfer samples to be analyzed into sample vials.

(5) Place the sample vials into the autosampler of an Easy-nLC 1000 UHPLC.

(6) Set up a method for each sample. Specify the names of the data files to be generated and the directory in which they will be stored. Load the LC and the MS methods written above (see "Equipment setup" for details).

(7) Start the LC-MS analysis and monitor it from time to time till it finishes.

\section{DATA ANALYSIS [TIMING 0.2-30 h]}

\section{Start a task}

(8) Double click the pLink 2 icon on desktop or the pLink installation folder to start pLink 2. Click "New..." to start a new task, change the task "Name" and choose "Location", then click "OK".

\section{Import .raw files and set up the extraction parameters (Fig. 5)}

(9) In the "MS data" panel, choose the "MS Data Format". "RAW" is the default data format. 


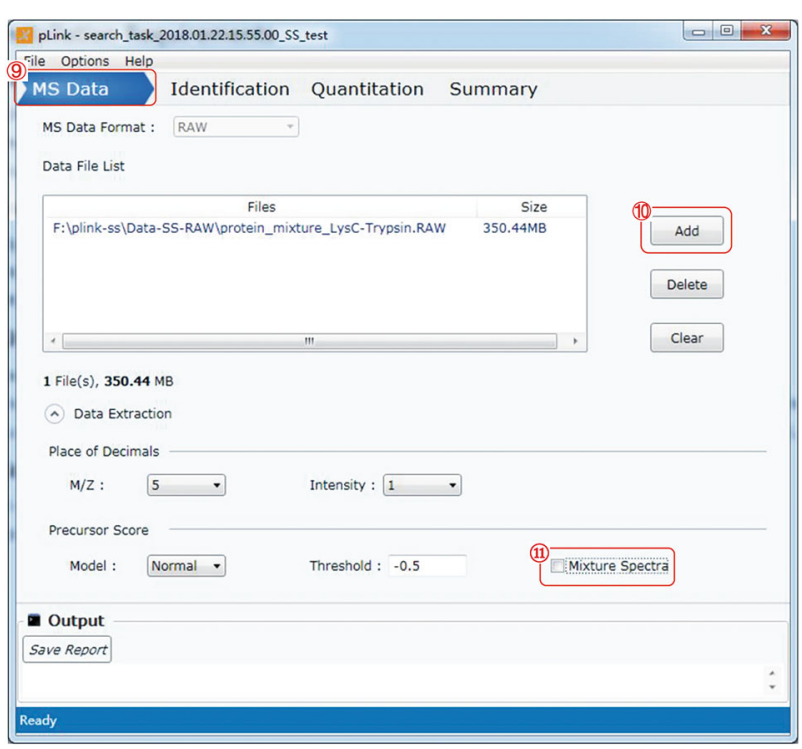

Fig. 5 Import raw file and set extraction parameters

[CRITICAL] Although pLink 2 can import ".mgf" files, we recommend the use of "raw" files as input. The "mgf" files extracted using other software tools may not be supported by pLink 2 , and ".ms2" files are not allowed.

(10) Click the "Add" button, choose the input file(s).

(11) Make sure to uncheck "Mixture Spectra". The default setting is on, but for disulfide bond identification it is better to turn it off.

\section{Set up the identification parameters (Fig. 6)}

(12) Click to switch to the "Identification" panel.

(13) For "Flow Type": choose "Disulfide bond (HCDSS)".

(14) In the "Set linkers" box, choose "SS" on the right side and click the arrow pointing to the left to transfer "SS" to the left side.

(15) Choose the database to use; you can add a new "fasta" file through the "Customize Database" option.

[CRITICAL] we recommend that you append the database of common contaminant proteins stored in pLink 2 to your "fasta" database file.

(16) Select the enzymes that had been used to digest the samples, for example, "Trypsin" for Lys-C/ trypsin digestion, "Glu-C.Trypsin" for Lys-C/trypsin/Glu-C digestion, and "non-specific" for Lys-C/ elastase or protease $\mathrm{K}$ digestion.

(17) Change the "mini peptide mass" to 400.

(18) Change the "mini peptide length" to 4 .

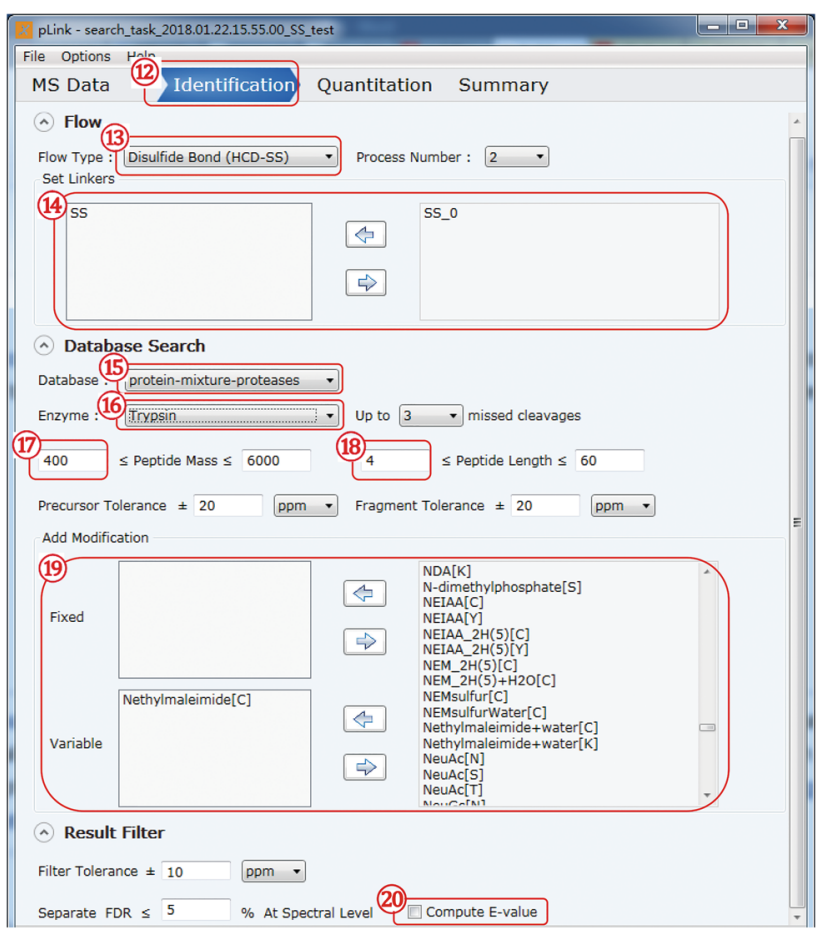

Fig. 6 Set up the identification parameters

(19) Select "N-Ethylmaleimide[C]" on the right side and transfer it to the "Variable" modification box on the left.

(20) Check "Compute $E$ value" to output $E$ value for each PSM.

[CRITICAL] pLink 2 uses a machine learning algorithm (SVM) to classify the target and decoy MS/MS spectra, and it only provides SVM-scores by default. Computing an $E$ value for each PSM is highly desirable.

\section{Check all the parameter settings and start search} (Fig. 7)

(21) Once the search parameters are complete, switch to the "Summary" panel.

(22) Double check the parameters. Go back and reset if anything is wrong.

(23) After verifying the parameters, click "Save" which will activate the "Start" button.

(24) Click "Start" and now the search begins.

(25) View results. When the "Output" panel displays "[pLink] Complete report", the html results will be shown in your default browser (IE or chrome) automatically. You can also view the "csv" format results in the "reports" folder of pLink 2. 


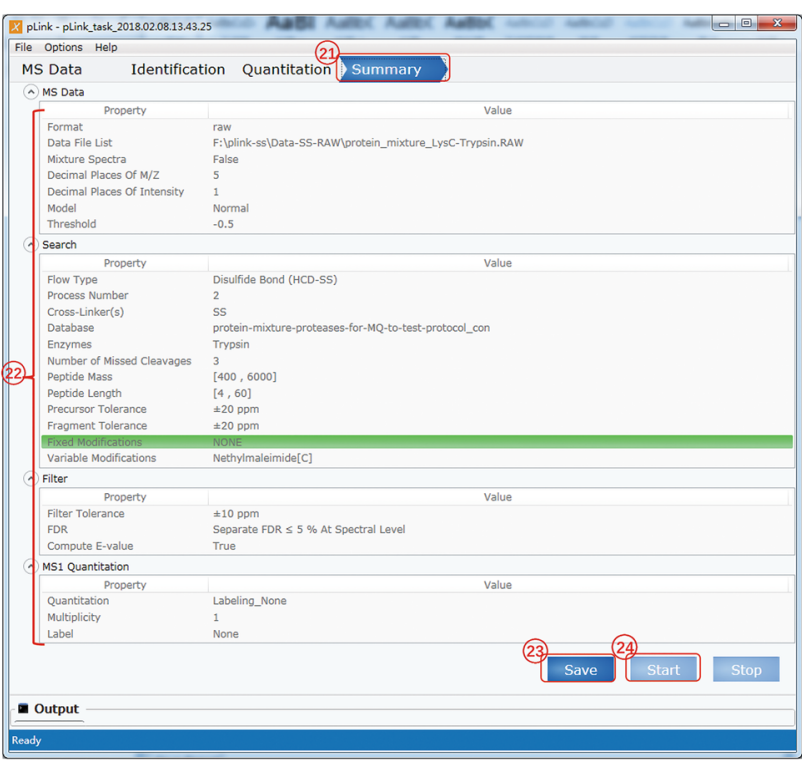

Fig. 7 Summary and starting to search

(26) To generate a concise summary of the disulfidelinked sites identified by pLink 2, copy the python script (attached to the end of this protocol) to your task folder, then open "Windows Explorer", type "cmd" in the location bar, and press "Enter" to open "Command Prompt". Lastly, enter the following in the command line:

- python SS_sim.py.

\section{VIEW MS/MS SPECTRA USING PLABEL}

\section{Load pLabel file (Fig. 8)}

(1) Double click the "pLabel" icon on desktop to open the window shown in Fig. 8. Click "FILE".

(2) Choose "Load pLabel File".

(3) Choose the "cross-linked.SS.plabel" file generated after a pLink 2 search.

\section{[? TROUBLESHOOTING]}

\section{Find the spectra of interest (Fig. 9)}

(5) Click "All".

(6) In the pop-up window, type in the scan number of interest, for example "3290", in the "Key Word" field.

(7) Click "Search".

(8) Choose the spectrum shown at the top.

(9) Click "OK".

\section{View matched ion of MS/MS spectra (Fig. 10)}

(10) Inspect the spectrum to see how well ion peaks match with calculated peptide fragments.

(11) Select the tab "Ion M/Z Deviation" to see mass deviations of matched ion peaks.

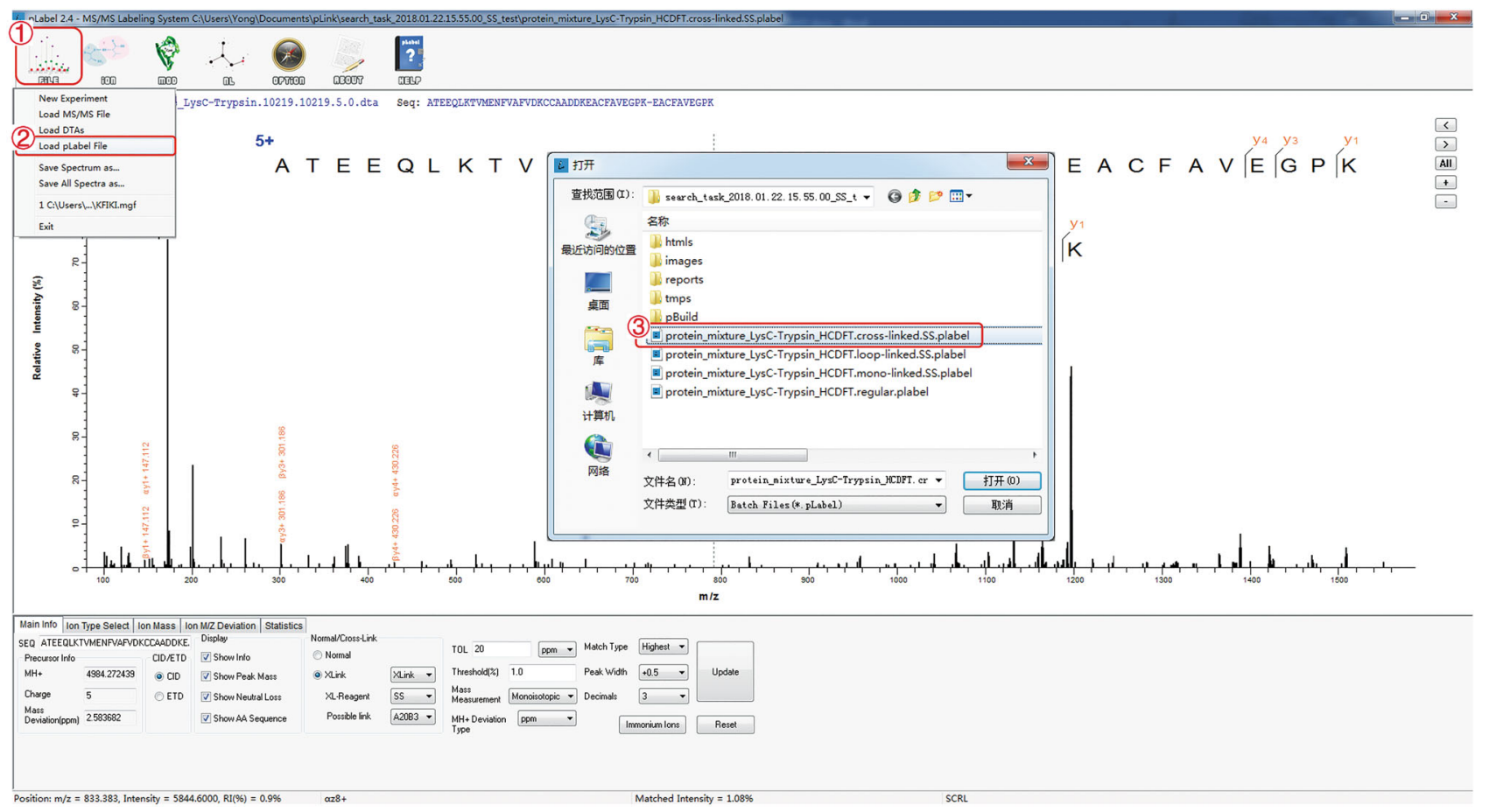

Fig. 8 Load pLabel file 


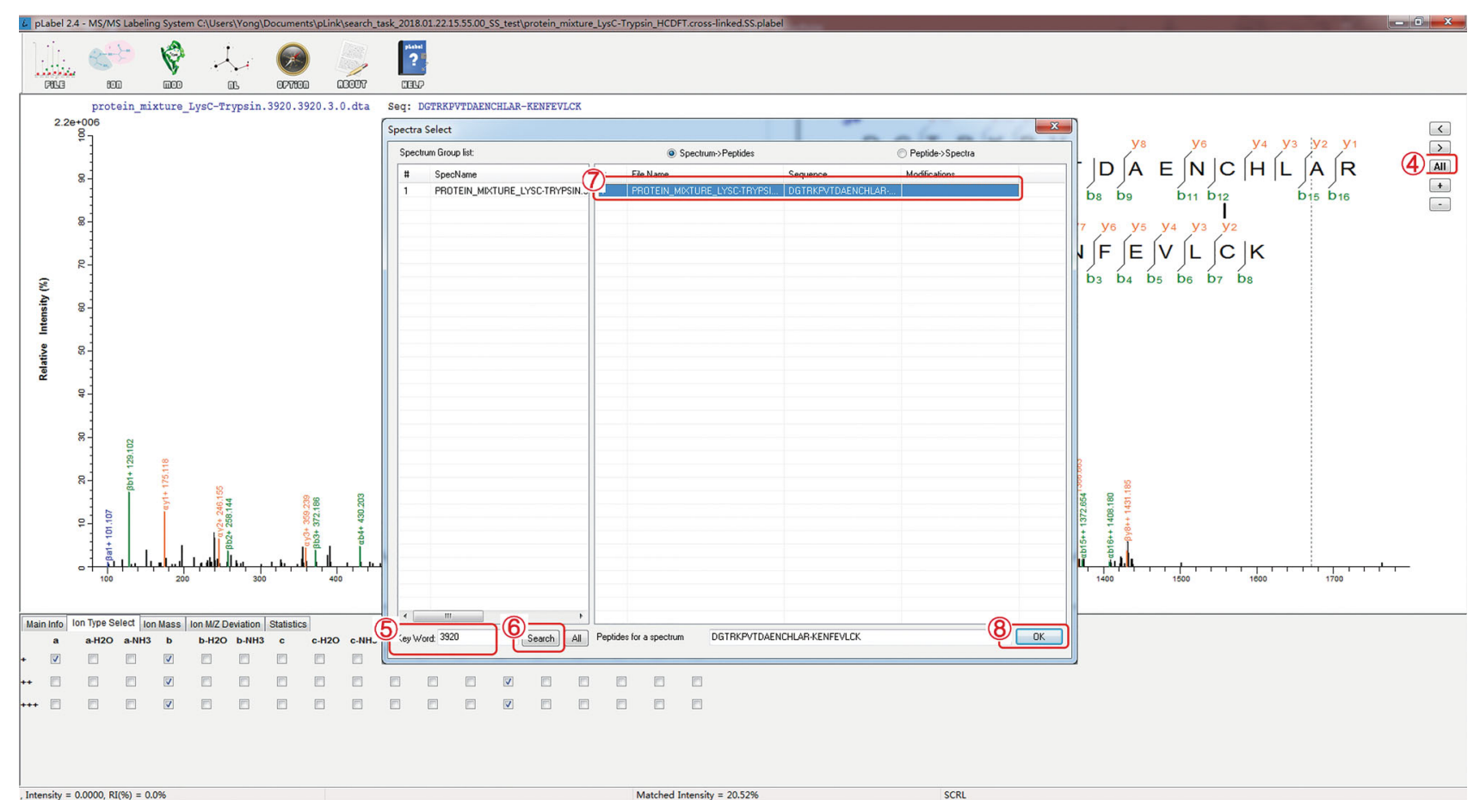

Fig. 9 Find a representative spectrum of a disulfide-linked peptide or peptide pair for manual inspection

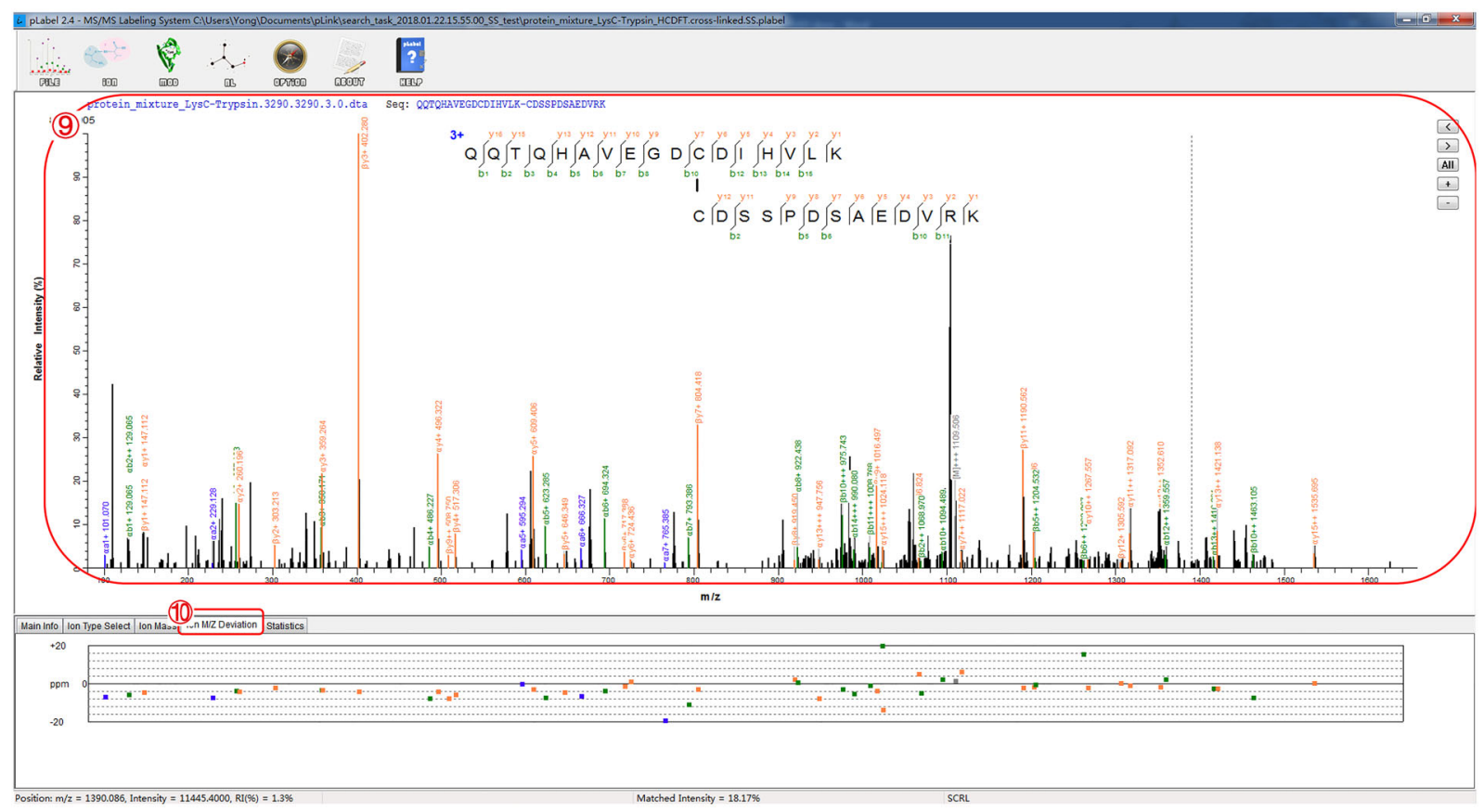

Fig. 10 View matched ion peaks and mass deviations

\section{RESULT ANALYSIS}

(1) Rank the identification results by the cysteine sites. If a cysteine residue is found to form disulfide bonds with more than one cysteine residue, it could be a result of disulfide scrambling or false identification. Compare the $E$ values, spectral counts, and intensities of these potentially conflicting identification results to try to distinguish a native disulfide bond from scrambled ones. This is 
based on the assumption that the native disulfide bond is the major form, so it should have higher signal intensity, higher spectral counts, and a smaller $E$ value, which indicates a higher confidence in identification.

(2) For purified proteins, such as pharmaceutical protein drugs, it is often required to map all the disulfide bonds in a protein. When some cysteines are missing from the disulfide identification results, one possibility is that they exist as free cysteines and the other is that they form disulfide bonds but these disulfide bonds have escaped identification. For the first possibility, one can expect free cysteines to be modified by NEM, so the corresponding modified linear peptides should be identifiable using conventional database search engines such as pFind. To find out whether the second possibility is true, we recommend reduction of disulfide bonds followed by alkylation and conventional database search to identify linear peptides; the cysteine-containing linear peptides can then be compared with those identified from the matched, non-reduced sample. In the case that a disulfide bond has escaped identification, first consider that the disulfide-containing peptide(s) may be too long or too short. Acting accordingly, choose proteases that will generate-concerning the cysteine residues in question-peptides of 6-20 (or better, 8-16) amino acids. Also, there may be an unknown modification near the missing disulfide bond. In this case, guess what it might be by sequence analysis with the help of modification prediction software, or use open search tools such as pFind 3.0 or Peaks to find possible modifications. Then, add the variable modification in pLink 2 search and see if it helps. Lastly, manual spectrum interpretation may help, but it requires a lot of time and experience.

\section{[? TROUBLESHOOTING]}

Troubleshooting advice can be found in Table 3.

Acknowledgements The authors would like to thank the Beijing Municipal Science and Technology Commission, the Ministry of Science and Technology of China, and the Natural Science Foundation of China (21475141) for research funding.

\section{Compliance with ethical standards}

Conflict of interest Shan Lu, Yong Cao, Sheng-Bo Fan, Zhen-Lin Chen, Run-Qian Fang, Si-Min He, and Meng-Qiu Dong declare that they have no conflict of interest.

Human and animal rights and informed consent This article does not contain any studies with human or animal subjects performed by any of the authors.

Open Access This article is distributed under the terms of the Creative Commons Attribution 4.0 International License (http:// creativecommons.org/licenses/by/4.0/), which permits unrestricted use, distribution, and reproduction in any medium, provided you give appropriate credit to the original author(s) and the source, provide a link to the Creative Commons license, and indicate if changes were made.

Table 3 Troubleshooting table

\begin{tabular}{|c|c|c|}
\hline Problem & Possible reason & Solution \\
\hline $\begin{array}{l}\text { Many scrambled disulfide bonds } \\
\text { are identified }\end{array}$ & $\begin{array}{l}\mathrm{pH} \text { is off; } \\
\text { NEM gone bad after storage }\end{array}$ & $\begin{array}{l}\text { Make sure that the pH of the urea buffer is } 6.5 \text {; } \\
\text { Make a fresh solution of NEM }\end{array}$ \\
\hline $\begin{array}{l}\text { The number of spectra of } \\
\text { disulfide-linked peptides are } \\
\text { too few }\end{array}$ & $\begin{array}{l}\text { Insufficient digestion, masses of disulfide- } \\
\text { linked peptides are too high; } \\
\text { Over-digestion by non-specific proteases }\end{array}$ & $\begin{array}{l}\text { Increase the amount of protease or the digestion time, } \\
\text { or add another protease; } \\
\text { Shorten the digestion time, try different time points }\end{array}$ \\
\hline $\begin{array}{l}\text { Certain disulfide bonds are not } \\
\text { identified }\end{array}$ & $\begin{array}{l}\text { Peptides are too long or too short, or too } \\
\text { complex, e.g., containing three peptides; } \\
\text { Unexpected modifications on the disulfide- } \\
\text { linked peptides }\end{array}$ & $\begin{array}{l}\text { Digest the samples with different proteases; } \\
\text { Try to identify the modification or treat with } \\
\text { glycosylase and see what happens }\end{array}$ \\
\hline $\begin{array}{l}\text { pLink } 2 \text { report "MS1 or MS2 not } \\
\text { completely extracted" }\end{array}$ & No MSFileReader installed & $\begin{array}{l}\text { Install MSFileReader https://github.com/ } \\
\text { pFindStudio/pLink2/wiki/FAQ\#how-to-install- } \\
\text { msfilereader }\end{array}$ \\
\hline Error in "loading label file" & $\begin{array}{l}\text { "mgf" file is missing from the directory of } \\
\text { the raw file }\end{array}$ & $\begin{array}{l}\text { Don't delete or move the "mgf" file. If it must be } \\
\text { moved, change the path in "plabel" file }\end{array}$ \\
\hline
\end{tabular}




\section{References}

Choi S, Jeong J, Na S, Lee HS, Kim H-Y, Lee K-J, Paek E (2009) New algorithm for the identification of intact disulfide linkages based on fragmentation characteristics in tandem mass spectra. J Proteome Res 9:626-635

Götze M, Pettelkau J, Schaks S, Bosse K, Ihling $\mathrm{CH}$, Krauth F, Fritzsche R, Kühn U, Sinz A (2012) StavroX-a software for analyzing crosslinked products in protein interaction studies. J Am Soc Mass Spectrom 23:76-87

Haniu M, Acklin C, Kenney WC, Rohde MF (1994) Direct assignment of disulfide bonds by Edman degradation of selected peptide fragments. Chem Biol Drug Des 43:81-86

Hartman MD, Figueroa CM, Arias DG, Iglesias AA (2016) Inhibition of recombinant aldose-6-phosphate reductase from peach leaves by hexose-phosphates, inorganic phosphate and oxidants. Plant Cell Physiol 58:145-155

Hogg PJ (2003) Disulfide bonds as switches for protein function. Trends Biochem Sci 28:210-214

Huang SY, Chen SF, Chen CH, Huang HW, Wu WG, Sung WC (2014) Global disulfide bond profiling for crude snake venom using dimethyl labeling coupled with mass spectrometry and RADAR algorithm. Anal Chem 86:8742-8750

Hung C-W, Koudelka T, Anastasi C, Becker A, Moali C, Tholey A (2016) Characterization of post-translational modifications in full-length human BMP-1 confirms the presence of a rare vicinal disulfide linkage in the catalytic domain and highlights novel features of the EGF domain. J Proteomics 138:136-145

Itakura $\mathrm{M}$, Iwashina $\mathrm{M}$, Mizuno $\mathrm{T}$, Ito $\mathrm{T}$, Hagiwara $\mathrm{H}$, Hirose $\mathrm{S}$ (1994) Mutational analysis of disulfide bridges in the type C atrial natriuretic peptide receptor. J Biol Chem 269:8314-8318

Liu F, van Breukelen B, Heck AJ (2014) Facilitating protein disulfide mapping by a combination of pepsin digestion, electron transfer higher energy dissociation (EThcD), and a dedicated search algorithm SlinkS. Mol Cell Proteomics 13:2776-2786

Liu Y, Sun W, Shan B, Zhang K (2017a) DISC: DISulfide linkage Characterization from tandem mass spectra. Bioinformatics 33:3861-3870

Liu Y, Xiao W, Shinde M, Field J, Templeton DM (2017b) Cadmium favors F-actin depolymerization in rat renal mesangial cells by site-specific, disulfide-based dimerization of the CAP1 protein. Arch Toxicol, 1-16
Lu S, Fan S-B, Yang B, Li Y-X, Meng J-M, Wu L, Li P, Zhang K, Zhang M-J, Fu Y (2015) Mapping native disulfide bonds at a proteome scale. Nat Methods 12:329

Mauney CH, Rogers LC, Harris RS, Daniel LW, Devarie-Baez NO, Wu H, Furdui CM, Poole LB, Perrino FW, Hollis T (2017) The SAMHD1 dNTP triphosphohydrolase is controlled by a redox switch. Antioxid Redox Signal 27:1317-1331

McCarthy AA, Haebel PW, Törrönen A, Rybin V, Baker EN, Metcalf P (2000) Crystal structure of the protein disulfide bond isomerase, DsbC, from Escherichia coli. Nat Struct Mol Biol 7:196

McDonagh B (2009) Diagonal electrophoresis for detection of protein disulphide bridges. In: Two-Dimensional Electrophoresis Protocols. Springer, pp. 305-310

Murad W, Singh R (2013) MS2DB + : a software for determination of disulfide bonds using multi-ion analysis. IEEE Trans Nanobiosci 12:69-71

Sharma D, Rajarathnam K (2000) 13C NMR chemical shifts can predict disulfide bond formation. J Biomol NMR 18:165-171

Wang J, Anania VG, Knott J, Rush J, Lill JR, Bourne PE, Bandeira N (2014) Combinatorial approach for large-scale identification of linked peptides from tandem mass spectrometry spectra. Mol Cell Proteomics 13:1128-1136

Wang T, Liang L, Xue Y, Jia P-F, Chen W, Zhang M-X, Wang Y-C, Li H-J, Yang W-C (2016) A receptor heteromer mediates the male perception of female attractants in plants. Nature 531:241

Wefing S, Schnaible V, Hoffmann D (2006) SearchXLinks. A program for the identification of disulfide bonds in proteins from mass spectra. Anal Chem 78:1235-1241

Wu S-L, Jiang H, Lu Q, Dai S, Hancock WS, Karger BL (2008) Mass spectrometric determination of disulfide linkages in recombinant therapeutic proteins using online LC-MS with electron-transfer dissociation. Anal Chem 81:112-122

Wu J, Yan Z, Li Z, Qian X, Lu S, Dong M, Zhou Q, Yan N (2016) Structure of the voltage-gated calcium channel Ca v 1.1 at 3.6 Å resolution. Nature 537:191

Wu Y, Zhu Y, Gao F, Jiao Y, Oladejo BO, Chai Y, Bi Y, Lu S, Dong M, Zhang C (2017) Structures of phlebovirus glycoprotein Gn and identification of a neutralizing antibody epitope. Proc Natl Acad Sci 114:E7564-E7573

$\mathrm{Xu} \mathrm{H}$, Zhang L, Freitas MA (2007) Identification and characterization of disulfide bonds in proteins and peptides from tandem MS data by use of the MassMatrix MS/MS search engine. J Proteome Res 7:138-144 